CLAWAR 2018: 21st International Conference on Climbing and

Walking Robots and the Support Technologies for Mobile Machines,

Panama City, Panama, 10-12 September 2018

\title{
TRAVELING-WAVE-TYPE WALL-CLIMBING ROBOT FOR AIRPLANE SURFACE INSPECTION
}

\author{
D. HAGIWARA*, N. TADAMI, T. AMAKAWA, Y. YAMADA, T. NAKAMURA \\ Department of Precision Mechanics, Chuo University, \\ 1-13-27 Kasuga, Bunkyo-Word, Tokyo 112-8551, Japan \\ *E-mail:d_hagiwara@bio.mech.chuo-u.ac.jp
}

Robots are expected to substitute for humans for work performed in locations at a height, such as the inspection of an airplane surface. The authors propose a traveling-wave-type wall-climbing robot simulating a snail movement. To this end, in this study, the negative pressure adsorption method was employed to develop a wall-climbing robot that could move on curved surfaces for high-altitude work.

Keywords: Wall-climbing robot; Airplane inspection; Traveling wave.

\section{Introduction}

High-altitude work includes the inspection of airplane surface, maintenance of high-rise buildings, maintenance of storage tanks, and operation of petrochemical product facilities at nuclear power plants, among others. These operations are performed regularly, wherein the assembling and footing of a tower wagon are necessary each time, thus affecting the time and cost. Furthermore, it is a problem to ensure the safety of workers performing work at high altitudes [1]. Therefore, to reduce time and cost and ensure worker safety, the development of a robot capable of performing these tasks is required.

The application of multicotters and the development of a wall-climbing robot can help realize high-altitude work robots. [2]-[6]. Multicotters have the advantages of light weight, easy transportation, and fast running speed of the robot. However, the robot is not robust against the weather and has low loading capacity, among other issues. [2]. Nevertheless, the wall-climbing robot is less influenced by weather and rain compared with the multicotter, and the load carrying capacity is higher [3]-[6]. In addition, the existing wall-climbing robot has adopted vacuum suction using a suction cup to obtain high adsorption power [3]. However, in vacuum adsorption, objects cannot adhere well to a rough surface or a surface with irregularities, and suction cup wear is a problem. Negative pressure adsorption by a fan, however, always discharges air to generate and maintain adsorption force. Therefore, adsorption to a rough surface or a surface with irregularities is possible. As such, in recent years, a negative pressure adsorptiontype wall-surface climbing robot has been proposed as a high-altitude work robot 
having high versatility [4]-[6]. The existing robot was confirmed to be adsorptive, and it could move on a rough surface. However, owing to the reduction in the adsorption power on the uneven surface, the robot cannot obtain sufficient grip and stacks [4] [5]. In order to solve this problem, a robot having a plurality of adsorption parts has been proposed; however, a passive joint and correspondence to a curved surface have not been realized to help increase the robot size [6].

To this end, the authors propose a traveling-wave-type mobile robot simulating a snail traveling [7]-[9]. In this robot, several adsorption units are respectively connected by a universal joint, and the robot progresses by the propagation of expansion and contraction between the units. At this time, the moving unit slides on the wall surface, and the unit that does not move is fixed with a strong force, such that each unit switches the frictional force [7] [8]. Consequently, the robot has a wide ground contact surface, thus maintaining a high adsorption force and stable traveling. Further, even if some of the units become insufficient owing to disturbance, they can be supported without being dropped by other units. Furthermore, the curved wall surface can also be traversed [9]. However, this robot can move only on magnetic surfaces to satisfy the properties of adsorption and friction switching with magnets.

In this study, we adopt the negative pressure adsorption method for the traveling-wave-type mobile robot and aim for the development of a wall-climbing robot to be used for high-altitude work. We propose a negative pressure adsorption unit and evaluate the traveling of the mobile robot composed of that unit, as well as examine the application to the work robot.

\section{Outline of High-altitude Work in Airplane Surface Inspection}

The surface of an airplane can be damaged by hail, bird collision, and lightning. Further, small scratches and dents are generated on the surface of the airplane during operation. Large damages are visually observed [10] and damages that are difficult to confirm visually are inspected using nondestructive inspection techniques such as penetrant inspection, magnetic particle inspection, X-ray inspection, and ultrasonic inspection.

The radius of curvature of the airplane surface is approximately $1 \mathrm{~m}$ or more [11]. In addition, gaps and steps of approximately $5 \mathrm{~mm}$ exist at locations of door installation and other installations. [12].

\section{Proposal of Wall-climbing Robot}

\subsection{Required performance for robots}

The inspection robot requires adsorption while traversing the airplane body surface, which is made of nonmagnetic duralumin, and it must be able to inspect equipment. Furthermore, the robot is required to traverse the doors, window gaps, 
and oversteps. Therefore, the robot must satisfy the following performance requirements:

- Adsorption movement on the wall surface and curved surface of nonmagnetic metal surface.

- High adsorption power capable of mounting nondestructive inspection equipment and other equipment.

- $\quad$ Ability to move on a surface with steps and gaps.

\subsection{Proposal of a robot for airplane surface inspection}

The outline of the proposed robot is shown in Fig. 1, and the method of operation of the robot is shown in Fig. 2. The robot consists of four units that adsorb negative pressure using a centrifugal fan. Each unit is connected by a universal joint and can be adsorbed to a curved surface (Fig.1 (b)). In addition, each unit changes its frictional force simultaneously with expansion and contraction (called highfriction unit during high friction, and low-friction unit during low friction). By this friction-force switching, the expansion and contraction of the unit facilitates the propagation, as shown in Fig. 2. Therefore, even during movement, a high adsorptive power can be maintained constantly and running stability can be secured. Furthermore, the lower part of the unit is a detachable part, and the friction material and seal material can be changed against the suction surface, as shown in Fig. 3. Consequently, the friction material and the sealing material can be changed with respect to the shape and material of the attracting surface.

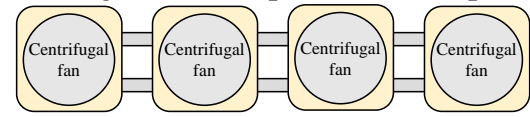

(a) Top view of a traveling-wave-type wall-climbing robot

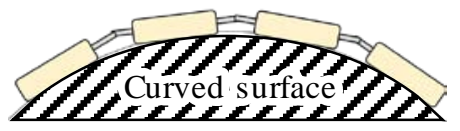

(b) Traveling-wave-type wall-climbing robot on a curved surface

Fig. 1 Overview of a traveling-wave-type wall-climbing robot
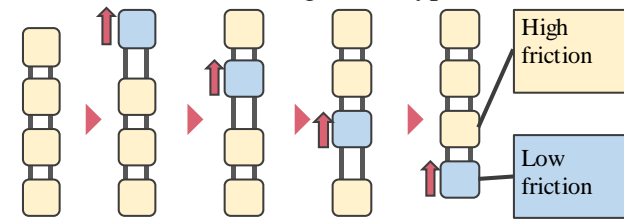

Fig. 2 Movement of a traveling-wave-type wall-climbing robot

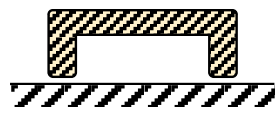

None

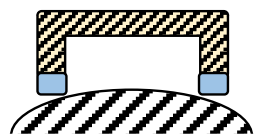

Under material A

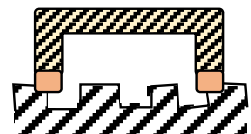

Under material B

Fig. 3 Under material of a traveling-wave-type wall-climbing robot 


\subsection{Calculation of frictional force and attractive force required for robot}

We calculate the frictional force and attractive force required for the adsorption at an angle $\theta$ made by the proposed robot to the wall surface. The dynamic equilibrium model of the robot is shown in Fig. 4, and the parameters are listed in Table 1. Because the unit changes the frictional force simultaneously with expansion and contraction, at the time of movement, a maximum of two low friction units are generated. Therefore, in the dynamic equilibrium model of the robot, these two are set as low friction units. Furthermore, the weight of the proposed unit is assumed to be $0.70 \mathrm{~kg}$, and the weight of the model unit including the weight of the loaded equipment is set to $1.5 \mathrm{~kg}$. The height of the center of gravity of the model unit is $70 \mathrm{~mm}$, which is the proposed unit height. Further, the robot is a rigid body, and the attraction force and friction force are concentrated loads acting on the center of the face. Here, Equation (1) represents the sum of the necessary attraction forces obtained from the force components perpendicular to the attracting surface. Equation (2) indicates the required attraction force obtained from the moment around the lower part of the unit. When the robot is regarded as a rigid body, the center of rotation of the moment is the point that is the most difficult to support (Fig. 4, point A), and the two low-friction units are located as the unit with the weakest supporting force. Equation (3) shows the necessary friction coefficient obtained from the force component horizontal to the attracting surface.

$$
\begin{gathered}
\left(A_{\mathrm{h}}+A_{\mathrm{l}}\right) \geqq 2 m g \cos \theta \\
A_{\mathrm{h}}(2 a+l)+A_{\mathrm{l}}(2 a+5 l) \geqq(4 a+6 l) m g \cos \theta+H_{\mathrm{G}} m g \sin \theta \\
\mu \geqq 2 m g \sin \theta /\left(A_{\mathrm{h}}+A_{\mathrm{l}}-2 m g \cos \theta\right)
\end{gathered}
$$

To calculate the maximum required adsorption force and friction coefficient, we calculate $\theta$ that maximizes the value of each right side. From the differential function of Equations (1)-(3), the right-hand side is maximum when $\theta=0^{\circ}, 87^{\circ}$, and $8.8^{\circ}$, respectively. Equations (4)-(6) show the expressions in which the numerical values of $\theta$, and the values listed in Table 1 , are substituted into the respective expressions.

$$
\begin{gathered}
A_{\mathrm{h}}+A_{\mathrm{l}} \geqq 29 \\
2 A_{\mathrm{h}}+7 A_{\mathrm{l}} \geqq 1.3 \times 10^{2} \\
\mu \geqq \frac{39.2 \sin \left\{\cos ^{-1}\left(\frac{39.2}{A_{\mathrm{h}}+A_{\mathrm{A}}}\right)\right\}}{\mathrm{A}_{\mathrm{h}}+\mathrm{A}_{\mathrm{l}}-39.2 \cos \left\{\cos ^{-1}\left(\frac{39.2}{\mathrm{~A}_{\mathrm{h}}+{ }_{A_{\mathrm{l}}}}\right)\right\}}
\end{gathered}
$$




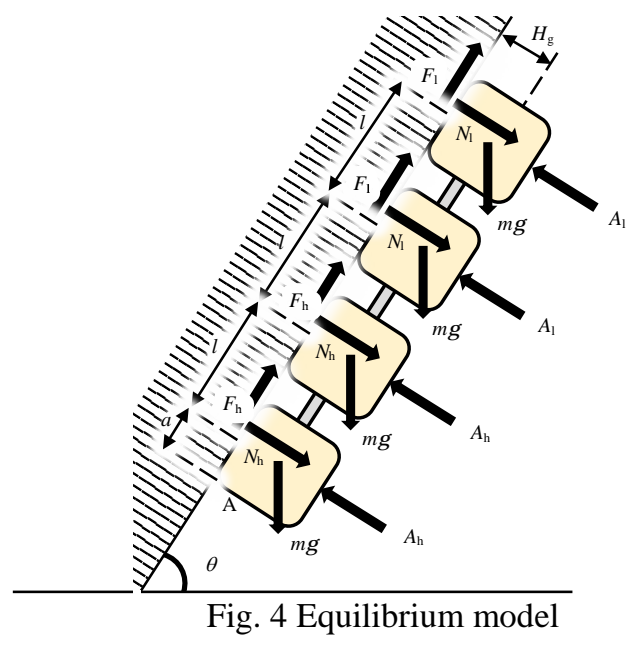

Table 1 Parameters

\begin{tabular}{|c|c|c|}
\hline & Parameter & Value \\
\hline$\theta$ & $\begin{array}{l}\text { Angle of an adhered } \\
\text { surface }\end{array}$ & $\begin{array}{l}0 \geqq \theta \\
\geqq 2 \pi\end{array}$ \\
\hline$A$ & Half length of a unit [m] & $\begin{array}{c}9.0 \times \\
10^{-2}\end{array}$ \\
\hline$H g$ & $\begin{array}{l}\text { Height of the center of } \\
\text { gravity }[\mathrm{m}]\end{array}$ & $\begin{array}{c}8.0 \times \\
10^{-2}\end{array}$ \\
\hline M & Mass of a unit [kg] & 2.0 \\
\hline G & $\begin{array}{l}\text { Acceleration of gravity } \\
{\left[\left[\mathrm{m} / \mathrm{s}^{2}\right]\right.}\end{array}$ & 9.8 \\
\hline$L$ & $\begin{array}{l}\text { Distance between each } \\
\text { center point of a unit [m] }\end{array}$ & 0.30 \\
\hline$A_{1}$ & $\begin{array}{l}\text { Adhesion force of a low- } \\
\text { friction unit [N] }\end{array}$ & - \\
\hline$A_{\mathrm{h}}$ & $\begin{array}{l}\text { Adhesion force of a high- } \\
\text { friction unit }[\mathrm{N}]\end{array}$ & - \\
\hline$N_{1}$ & $\begin{array}{l}\text { Normal force of a low- } \\
\text { friction unit }[\mathrm{N}]\end{array}$ & - \\
\hline$N_{\mathrm{h}}$ & $\begin{array}{l}\text { Normal force of a high- } \\
\text { friction unit [N] }\end{array}$ & - \\
\hline$F_{1}$ & $\begin{array}{l}\text { Frictional force of a low- } \\
\text { friction unit }[N]\end{array}$ & - \\
\hline$F_{\mathrm{h}}$ & $\begin{array}{l}\text { Frictional force of a high- } \\
\text { friction unit }[\mathrm{N}]\end{array}$ & - \\
\hline
\end{tabular}

\section{Running Experiment}

\subsection{Running experiment on a horizontal plane}

The developed robot is shown in Fig. 5, and the robot parameters are listed in Table 2. The moving speed of the robot was measured with a horizontal metal surface. In addition, the unit of this robot adopted a sponge rubber having a large friction coefficient to the airplane fuselage surface and a sealing effect to the material of the lower part of the unit [11]. Table 3 lists the adsorption force and friction coefficient of this unit during high adsorption and low adsorption. These values satisfy Equations (4)-(6). Therefore, the robot can be adsorbed on the wall surface at an arbitrary angle.

After the beginning of expansion and contraction, the robot requires $25 \mathrm{~s}$ until one extension and contraction has been propagated to all the units and advanced (hereinafter referred to as a stroke), and the robot advances by $20 \mathrm{~mm}$ with one stroke. The time and moving distance necessary for the stroke depend on the performance of the linear motion servomotor. 


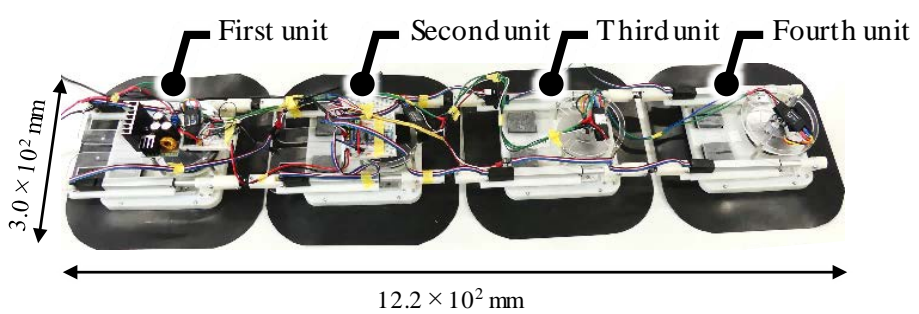

(a) Overview of a traveling-wave-type wall-climbing robot

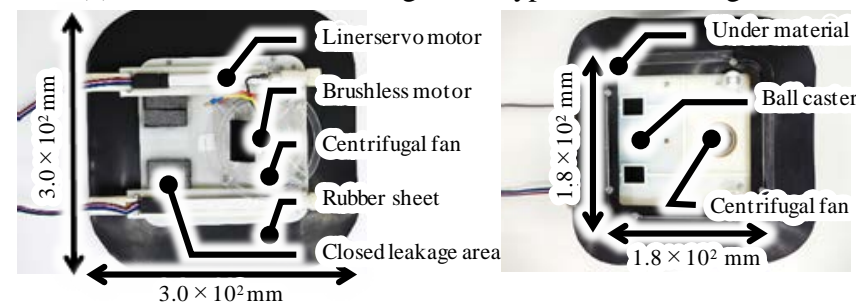

(b) Negative pressure suction unit

Fig. 5 Traveling-wave-type wall-climbing robot

Table 2 Specifications of the travelingwave-type wall-climbing robot

\begin{tabular}{cc}
\hline Parameter & Value \\
\hline Weight $[\mathrm{kg}]$ & 3.0 \\
Length $[\mathrm{mm}]$ & $1.2 \times 10^{3}$ \\
Width $[\mathrm{mm}]$ & $3.0 \times 10^{2}$ \\
Height $[\mathrm{mm}]$ & 80 \\
Speed $[\mathrm{mm} / \mathrm{s}]$ & 0.80 \\
Time required for a stroke [s] & 25 \\
Distance travelled in a stroke & 20 \\
[mm]
\end{tabular}

Table 3 Measured values

\begin{tabular}{cc}
\hline Parameter & Value \\
\hline $\begin{array}{c}\text { Adhesion force of } \\
\text { high-friction unit[N] }\end{array}$ & 61 \\
$\begin{array}{c}\text { Adhesion force of } \\
\text { low-friction unit [N] } \\
\text { Coefficient of friction }\end{array}$ & 30 \\
\hline
\end{tabular}

\subsection{Wall climbing and slip of robot}

The developed robot can climb on a metal wall, as shown in Fig. 6. The trajectory of each unit of the robot at this time is shown in Fig. 7, and the running state is shown in Fig. 8. Figure 7 shows that each unit slips immediately after it is extruded into a linear servomotor. Further, the differences in the feed speeds of the linear servomotor that pushes the unit from the bottom at the time of expansion and contraction propagation, and the linear motion servo motor that draws from above were visually confirmed. This may be attributed to the difference in load applied by its own weight. Furthermore, from this difference in feed speed, the motor pulling the unit from the above stops first. Therefore, force is applied temporarily to the unit in the direction opposite to the climbing direction, and as shown in Fig. 7, slip occurs immediately after the extension of the unit. 


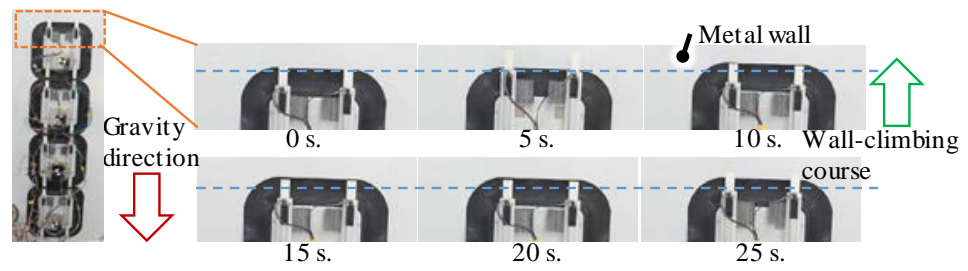

Fig. 6 Example of wall-climbing experiment

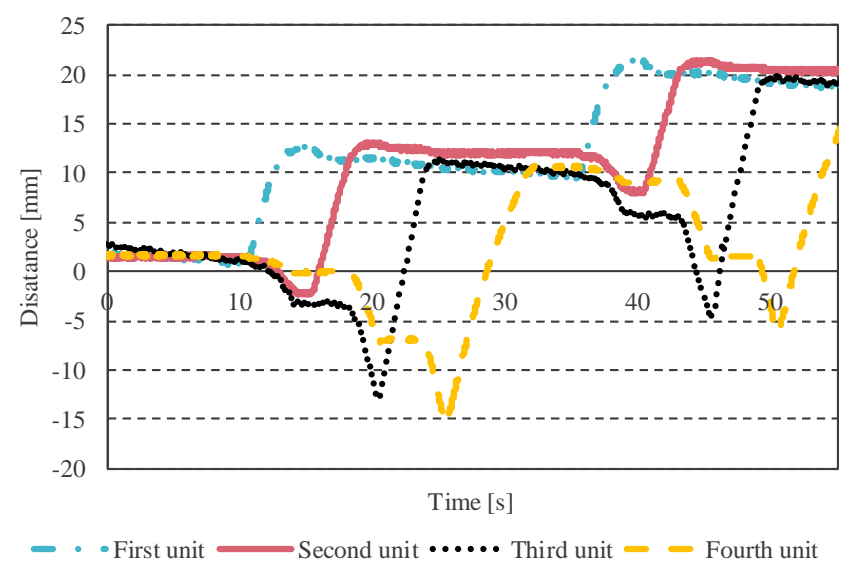

Fig. 7 Trajectory of the units

\section{Conclusion}

In this study, we developed a traveling-wave-type wall-climbing robot for highaltitude work such as inspection of an airplane surface. The main conclusions obtained from the study are as follows:

1. A new negative pressure absorption-wall-type mobile robot was proposed.

2. The frictional force and adsorption force necessary for the robot to traverse the surface were calculated.

3. A running experiment was conducted considering a horizontal surface and a vertical wall surface. We confirmed that the robot satisfied the performance requirements considered to be necessary for airplane inspection.

In the future, we will perform a running experiment on a ceiling surface, a curved surface, a step within $5 \mathrm{~mm}$, and on a gap. We will devise an inspection method suitable for this robot and perform mounting of the inspection equipment. In addition, if necessary, we will reconsider the used actuator and improve the running speed of the robot. 


\section{References}

1. DEATH ON THE JOB, AFL-CIO Safety and Health Department (April 2017).

2. Al Habsi, S., Shehada, M., Abdoon, M., Mashood, A., and Noura, H., Integration of a Vicon Camera System for Indoor Flight of a Parrot AR Drone, International Symposium on Mechatronics and its Applications (ISMA) (07 January 2016).

3. Zhiwei, X., Muhua, C., and Qingji, G., The structure and defects recognition algorithm of an airplane surface defects inspection robot, IEEE International Conference on Information and Automation (June 22 -25, 2009).

4. Zhou, Q., and Li, X., Design of Wall-climbing Robot Using Electrically Activated Rotational-flow Adsorption Unit, IEEE/RSJ International Conference on Intelligent Robots and Systems (IROS) (October 9-14, 2016).

5. T. Amakawa, T. Yamaguchi, N. Tadami, Y. Yamada and T. Nakamura, DEVELOPMENT OF OMNIDIRECTIONAL WALL-CLIMBING ROBOT FOR AIRPLANE INSPECTION, International Conference on Climbing and Walking Robots and the Support Technologies for Mobile Machines (September 11-13, 2017).

6. Wang, K., Liu, R., and Qu, Y., Development of a Double-Cavity Climbing Robot for On-Site Inspection of Glass-Curtain-Walls, IEEE International Conference on Information and Automation Yinchuan (August 2013).

7. K. Satoh and T. Nakamura, Development of an omni-directional mobile robot based on snail locomotion, in Proc. 7th Int. Conf. Climbing and Walking Robots and Support Technologies for Mobile Machines, pp. 144-152 (2007).

8. T. Ogawa, M. Yamoto, and T. Nakamura, Proposed omnidirectional locomotion strategy for traversing-wave-type mobile robot, in Proc. 14th Int. Conf. on Climbing and Walking Robots and the Support Technologies for Mobile Machines, pp. 127-134, (2011).

9. T. Go, T. Osawa, T. Ogawa, and T. Nakamura, Development of Traveling Wave Type Omnidirectional Wall Climbing Robot using Permanent Magnetic Adhesion Mechanism and Proposal of Locomotion Strategy for the Robot, in Proc. 2014 IEEE/ASME Int Conf. Adv. Intel. Mechatron., pp.1000-1010, (2014).

10. T. Amakawa, T. Yamaguchi, Y. Yamada and T. Nakamura, Proposing an adhesion unit for an traveling-wave-type, omnidirectional wall-climbing robot in airplane body inspection applications, IEEE International Conference on Mechatronics, (Feb. 2017).

11. T. Amakawa, T. Yamaguchi, Y. Yamada, T. Nakamura, Development of an Adhesion Unit for a Traveling-wave-type, Omnidirectional Wall-climbing Robot in Airplane Body Inspection, EEE International Conference on Advanced Intelligent Mechatronics, (July 3-7, 2017).

12. T. Ymaguchi, T. Go, T. Amakawa, Y. Yamada and T. Nakamura, Development of Negative Pressure Suction Mechanism in Omnidirectional Wall-climbing Robot for Inspect of Airplanes, International Conference on Climbing and Walking Robots and the Support Technologies for Mobile Machines, pp.106114 (2016). 